\title{
Sensorineural Hearing Loss in Rheumatoid Arthritis
}

\author{
Shelja Deswal ${ }^{1}$, Jyoti Yadav ${ }^{2}$, Mridul Yadav ${ }^{3}$, Beena Singh ${ }^{4}$ \\ ${ }^{1}$ Assistant Professor, ${ }^{2}$ Senior Professor and Head of Department, ${ }^{3}$ Associate Professor, ${ }^{4}$ Professor, \\ Department of Physiology, Pt. B.D. Sharma, PGIMS, Rohtak, India
}

Corresponding Author: Shelja Deswal

\begin{abstract}
Introduction: Rheumatoid arthritis (RA) is a chronic multisystem disease of unknown etiology is characterized by persistent inflammatory synovitis, usually involving peripheral joints in a symmetric distribution. RA is well known to affect many organ systems, including the auditory system and can involve the incudomalleolar and incudostapedial joints altering the ossicular mechanics in response to static air pressure modifications.

Objective: This study evaluates the degree of sensorineural hearing loss in patients with rheumatoid arthritis (RA)

Material and Methods: This study was conducted in the Department of Physiology in collaboration with departments of Medicine and ENT Pt. B.D. Sharma PGIMS, Rohtak. 25 rheumatoid arthritis female patients with disease duration of more than five years as per 1987 criteria of American college of rheumatology were included in the study to study the effect of rheumatoid arthritis on hearing. 25 healthy volunteer females were included in control group. Audiological evaluation was based on pure tone audiometry.
\end{abstract}

Results: We observed a high incidence of hearing loss in rheumatoid arthritis patients as compared to corresponding age and sex matched controls. Nine RA (36\%) cases, were having hearing threshold more than $25 \mathrm{~dB}$. Of the total of $36 \%$ patients having hearing loss $24 \%$ patients had sensorineural hearing loss. Bilateral hearing loss was seen in $8 \%$ of cases.

Conclusion: Based on our study it can be postulated that patients with RA are at higher risk of hearing impairment.

Keywords: Rheumatoid arthritis, hearing, sensorineural, audiometry

\section{INTRODUCTION}

Rheumatoid arthritis (RA), a chronic multisystem disease of unknown etiology is characterized by persistent inflammatory synovitis, usually involving peripheral joints in a symmetric distribution. The potential of the synovial inflammation to cause cartilage damage, bone erosions and subsequent changes in joint integrity is the hallmark of the disease. Onset is most frequent during the fourth and fifth decades of life with $80 \%$ of patients developing the disease between the age of 35 to 50 years. [1] RA is a systemic disease often associated with cutaneous and organ-specific extra-articular manifestations (EAM). ${ }^{[2]}$ Rheumatoid arthritis is well known to affect many organ systems, including the auditory system and measures of hearing may be related to indices of RA disease activity. ${ }^{[3]}$ It can involve the incudo-malleolar and incudostapedial joints altering the ossicular mechanics in response to static air pressure modifications. These joints are true diarthroses and therefore subject to the same rheumatic lesions as any other articulation in the body. ${ }^{[4]}$ Perisacular tissue surrounding the endolymphatic sac contains the necessary components for an immunological reaction. In addition, the inner ear is capable of producing an autoimmune response to sensitized cells that can enter the cochlea 
from the circulatory system through the spiral modiolar vein. ${ }^{[5]}$ Pure tone audiometry is the gold standard for diagnostic audiological testing. From pure-tone air conduction (AC) and bone conduction (BC) thresholds, the degree or magnitude, configuration and type of hearing loss are determined. AC thresholds assess the entire auditory pathway. ${ }^{[6]}$

\section{Aim \& Objective}

This study evaluates the degree of sensorineural hearing loss in patients with rheumatoid arthritis (RA.)

\section{MATERIAL AND METHODS}

This study was conducted in the Department of Physiology in collaboration with departments of Medicine and ENT Pt. B.D. Sharma PGIMS, Rohtak. 25 rheumatoid arthritis female patients with disease duration of more than five years as per 1987 criteria of American college of rheumatology were included in the study to study the effect of rheumatoid arthritis on hearing. 25 healthy volunteer females were included in control group. Audiological evaluation was based on pure tone audiometry.

Inclusion criteria: Patients of rheumatoid arthritis with disease duration of more than five years as per 1987 ACR criteria were included in the study. ${ }^{[7]}$

Exclusion criteria: Patients with the following diseases were excluded: Ear discharge and deafness, Renal diseases, Hepatic diseases, Chronic respiratory diseases, Diabetes Mellitus, Uncontrolled hypertension and Pregnant or lactating mothers.

An informed consent was taken from the patients to participate in the study and study was well within the ethical norms.

\section{Statistical Analysis}

The data collected in the study was compiled and analyzed by using student's 't' test.

\section{RESULT}

- The difference in hearing threshold at $250 \mathrm{~Hz}$ of both right and left ears for air conduction between group I (22.22 \pm 2.43$)$ and II $(24.32 \pm 2.49)$ was statistically significant $(\mathrm{p}<0.05)$.

- The difference in hearing threshold at $500 \mathrm{~Hz}$ of both right and left ears for air conduction between group I (20.92 \pm 2.24$)$ and group II $(22.56 \pm 5.25)$ was statistically significant $(\mathrm{p}<0.05)$.

- The difference in hearing threshold at $1000 \mathrm{~Hz}$ of both right and left ears for air conduction between group I (20.54 \pm 2.26$)$ and group II (23.58 \pm 6.03$)$ was statistically significant $(\mathrm{p}<0.05)$.

- The difference in hearing threshold at $2000 \mathrm{~Hz}$ of both right and left ears for air conduction between group I (20.96 \pm 2.71$)$ and group II $(23.48 \pm 6.99)$ was statistically significant $(\mathrm{p}<0.05)$.

- The difference in hearing threshold at $4000 \mathrm{~Hz}$ of both right and left ears for air conduction between group I (22.08 \pm 2.92$)$ and group II $(26.88 \pm 9.42)$ was statistically significant $(\mathrm{p}<0.05)$.

- The difference in hearing threshold at $8000 \mathrm{~Hz}$ of both right and left ears for air conduction between group I (22.24 \pm 3.12$)$ and group II (28.96 \pm 17.04$)$ was statistically significant $(\mathrm{p}<0.05)$. There was mild hearing loss at $4 \mathrm{k}$ and $8 \mathrm{k}$ frequencies.

- The difference in hearing threshold at $250 \mathrm{~Hz}$ of both right and left ears for bone conduction between group I (12.76 \pm 3.28$)$ and group II $(14.40 \pm 5.40)$ was statistically insignificant $(\mathrm{p}>0.05)$.

- The difference in hearing threshold at 500 and $1000 \mathrm{~Hz}$ of both right and left ears for bone conduction between group I $(11.24 \pm 2.35,12.96 \pm 3.13)$ and group II

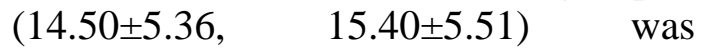
statistically significant $(\mathrm{p}<0.05)$.

- The difference in hearing threshold at $2 \mathrm{k}, 4 \mathrm{k}$ and $8 \mathrm{k} \mathrm{Hz}$ of both right and left ears for bone conduction between group I $(13.52 \pm 3.38,11.68 \pm 3.30,11.32 \pm 2.66)$ and group II $(17.62 \pm 6.38,17.88 \pm 7.97$, $16.88 \pm 9.83)$ was very highly statistically significant $(\mathrm{p}<0.001)$ (Table 1$)$. 
Table 1: Comparison of hearing threshold intensity at various frequencies of air and bone conduction of right and left ear between group I and group II

\begin{tabular}{|l|l|l|l|}
\hline Parameters & $\begin{array}{c}\text { Group I(dB) } \\
\text { (Mean } \pm \text { SD) }\end{array}$ & $\begin{array}{c}\text { Group II(dB) } \\
\text { (Mean } \pm \text { SD) }\end{array}$ & p value \\
\hline Air conduction \\
\hline $250 \mathrm{~Hz}$ & $22.22 \pm 2.43$ & $24.32 \pm 2.49$ & $<0.05$ \\
\hline $500 \mathrm{~Hz}$ & $20.92 \pm 2.24$ & $22.56 \pm 5.25$ & $<0.05$ \\
\hline $1000 \mathrm{~Hz}$ & $20.54 \pm 2.26$ & $23.58 \pm 6.03$ & $<0.05$ \\
\hline $2000 \mathrm{~Hz}$ & $20.96 \pm 2.71$ & $23.48 \pm 6.99$ & $<0.05$ \\
\hline $4000 \mathrm{~Hz}$ & $22.08 \pm 2.92$ & $26.88 \pm 9.42$ & $<0.05$ \\
\hline $8000 \mathrm{~Hz}$ & $22.24 \pm 3.12$ & $28.96 \pm 17.04$ & $<0.05$ \\
\hline \multicolumn{4}{|c|}{ Bone conduction } \\
\hline $250 \mathrm{~Hz}$ & $12.76 \pm 3.28$ & $14.40 \pm 5.40$ & $>0.05$ \\
\hline $500 \mathrm{~Hz}$ & $11.24 \pm 2.35$ & $14.50 \pm 5.36$ & $<0.05$ \\
\hline $1000 \mathrm{~Hz}$ & $12.96 \pm 3.13$ & $15.40 \pm 5.51$ & $<0.05$ \\
\hline $2000 \mathrm{~Hz}$ & $13.52 \pm 3.38$ & $17.62 \pm 6.38$ & $<0.001$ \\
\hline $4000 \mathrm{~Hz}$ & $11.68 \pm 3.30$ & $17.88 \pm 7.97$ & $<0.001$ \\
\hline $8000 \mathrm{~Hz}$ & $11.32 \pm 2.66$ & $16.88 \pm 9.83$ & $<0.001$ \\
\hline
\end{tabular}

\section{DISCUSSION \& CONCLUSION}

In our study hearing loss was calculated with an average of four frequencies $500 \mathrm{~Hz}, 1000 \mathrm{~Hz}, 2000 \mathrm{~Hz}$ and $4000 \mathrm{~Hz}$. Hearing threshold more than $25 \mathrm{~dB}$ was considered as hearing loss. We observed a high incidence of hearing loss in rheumatoid arthritis patients as compared to corresponding age and sex matched controls.

Nine RA (36\%) cases, were having hearing threshold more than $25 \mathrm{~dB}$. Of the total of $36 \%$ patients having hearing loss $24 \%$ patients had SNHL, 8\% had conductive hearing loss, and $4 \%$ had mixed hearing loss. Bilateral hearing loss was seen in $8 \%$ of cases. One patient had an isolated dip at $4000 \mathrm{~Hz}$ but did not have hearing loss. Nine patients were having hearing loss in average of frequencies $500 \mathrm{~Hz}, 1 \mathrm{k}, 2 \mathrm{k}$ and $4 \mathrm{k}$ with an average threshold $33.18 \mathrm{~dB}$ with a hearing loss of $8.18 \mathrm{~dB}$ (mild hearing loss). However, the involvement of $8000 \mathrm{~Hz}$ was associated with higher hearing loss. The average hearing threshold at $8000 \mathrm{~Hz}$ was 50 $\mathrm{dB}$ with hearing loss of $25 \mathrm{~dB}$ (moderate hearing loss).

Takastu et al also demonstrated that there is increased SNHL in patients with RA, which may result from systemic inflammation and tissue injury. The frequency of SNHL in the patients with RA was higher than in normal controls (36.1\% versus $13.9 \%) .{ }^{[8]}$ This was in accordance to our study.
Baradaranfar and Doosti in a case control study reported that most of the patients of RA with ear disorders show sensorineural hearing loss (SNHL), though conductive hearing loss (CHL) and in some of them mixed hearing loss is also observed. The authors reported that the audiometric tests in different frequencies show that hearing threshold in high frequencies specially in $8000 \mathrm{~Hz}$ had a significant difference between two groups, $\mathrm{p}=0.017$ in right ear and $\mathrm{p}=0.003$ in left ear. SNHL of the cochlear variation is a common finding in patients with RA whereas conductive loss and mixed HL also seen. SNHL may be the result of the extra-articular manifestation of the disease. ${ }^{[9]}$

Ozcan et al in a controlled study observed $72.2 \%$ of the individuals had hearing loss in their group of 37 patients with RA. The prevalence of the hearing impairment was significantly higher in the RA group, and the majority was bilateral $(\mathrm{P}<0.001)$. Of the patients, $35.1 \%$ had sensorineural (SN), $24.3 \%$ had conductive loss, and $10.8 \%$ had a mixed type of hearing loss. The incidence of hearing loss in our study was less than those reported by Ozcan et al. ${ }^{[10]}$ The probable site of involvement responsible for the SNHL was the cochlea and discontinuity of the ossicles was responsible for the conductive hearing loss.

Salvinelli et al in their study evaluated the prevalence and features of hearing impairment in $28 \mathrm{RA}$ patients who were subjected to pure tone audiometry at 250, 500, 1000, 2000 and $4000 \mathrm{~Hz}$. Air and bone conduction thresholds and air-bone gaps were evaluated. On audiological assessment 24 RA patients showed bilateral hearing loss. Of these, 10 presented with sensorineural hearing loss, 8 with a mixed type hearing impairment and 6 with conductive hearing impairment. ${ }^{[11]}$

Garcia et al evaluated the characteristics of hearing loss in 194 RA patients. They were subjected to pure tone audiometry and western blot for anticochlear antibodies. Sensorineural 
hearing loss (SNHL) was detected in $42.7 \%$ of patients. Western blot test was positive in $12 \%$ of patients. ${ }^{[12]}$

Magaro et al observed sensorineural hearing loss in 55\% of RA patients and reported a correlation between disease activity and rheumatoid factor positivity. ${ }^{[13]}$

Kastanioudakis et al in their study investigated the presence of sensorineural hearing loss and the possible causes for it. RA patients were subjected to pure tone audiometry, impedance audiometry, acoustic reflex, decay and acoustic reflex latency test. Sensorineural hearing loss $>20 \mathrm{~dB}$ in $44.4 \%$ and prolongation of acoustic reflex latency in $10 \%$ which was found to be correlated with temporomandibular joint involvement and the presence of rheumatoid factor was reported. Inner ear involvement in RA was shown by mild, symmetric, bilateral sensorineural hearing loss of cochlear type, normal acoustic reflex thresholds, nondecay and prolongation of acoustic reflex latency. ${ }^{[14]}$

Based on our study it can be postulated that patients with RA are at higher risk of hearing impairment.

Acknowledgment: No authors received funding for preparation of the manuscript. The authors declare that there is no conflict of interest.

\section{Conflict of Interest: None}

Source of Funding: None

\section{Ethical Approval: Approved}

\section{REFERENCES}

1. Lipsky PE. Rheumatoid Arthritis. In: Fauci AS, Kasper DL, Braunwald E, Hauser SL, Longo DL, Jameson JL, editors. Harrison's principles of internal medicine. 17th ed. New Delhi: McGraw Hill; 2008. p. 2083-8.

2. Prete M, Racanelli V, Digiglio L,et al. Extraarticular manifestations of rheumatoid arthritis: an update. Autoimmune Rev. 2011; 11:123-31.
3. Murdin L, Patel S, Walmsley J, et al. Hearing difficulties are common in patients with rheumatoid arthritis. Clin. Rheumatol. 2008; 27:637-40.

4. Colletti V, Fiorino FG, Bruni L, et al. Middle ear mechanics in subjects with rheumatoid arthritis. Audiology. 1997;36:136-46.

5. Hurley RM, Sells JP. Autoimmune inner ear disease. Am J Audiol. 1997;6:22-30.

6. Roeser RJ, Valente M, Dunn HH. Diagnostic procedures in audiology. In: Roeser RJ, Valente M, Dunn HH, editors. Audiology diagnosis. New York: Thieme; 2007. p. 3

7. Arnett FC, Edworthy SM, Bloch DA, et al. The American Rheumatism Association revised criteria for the classification of rheumatoid arthritis. Arthritis Rheum. 1988;31:315-24.

8. Takatsu M, Higaki M, Kinoshita H, et al. Ear involvement in patients with rheumatoid arthritis. OtolNeurotol. 2005;26:755-61.

9. Baradaranfar MH, DoostiAfsanch. A survey of relationship between rheumatoid arthritis and hearing disorders.Acta Medica Iranica 2010;48: 371-73.

10. Ozcan M, Karakus MF, Gündüz $\mathrm{OH}$, et al. Hearing loss and middle ear involvement in rheumatoid arthritis. Rheumatol Int. 2002;22:16-9.

11. Salvinelli F, D’Ascanio L, Casale M, et al. Auditory pathway in rheumatoid arthritis. A comparative study and surgical perspectives. Acta Oto-laryngol. 2006;126:32-6.

12. García Callejo FJ, ConillTobías N, Muñoz Fernández $\mathrm{N}$ et al. Hearing impairment in patients with rheumatoid arthritis. Acta Otorrinolaringol.2007;58:232-8.

13. Magaro M, Zoli A, Altomonte L, Mirone L, Corvino G, Digirolamo S, et al. Sensorineural hearing loss in rheumatoid arthritis. Clin Exp Rheumatol. 1990;8:487-9.

14. Kastanioudakis I, Skevas A, Danielidis V, et al. Inner ear involvement in rheumatoid arthritis: A prospective clinical study. J Laryngol Otol. 1995;109:713-8.

How to cite this article: Deswal S, Yadav J, Yadav $\mathrm{M}$ et.al. Sensorineural hearing loss in rheumatoid arthritis. Int J Health Sci Res. 2021; 11(12):79-82. DOI: https://doi.org/ 10.52403/ijhsr.20211212 